Check for updates

Cite this: RSC Adv., 2019, 9, 21786

\title{
Synthesis of Sn/Ag-Sn nanoparticles via room temperature galvanic reaction and diffusion $\uparrow$
}

\author{
Min Jia Saw, Mai Thanh Nguyen, (D) Shilei Zhu, (D) Yongming Wang \\ and Tetsu Yonezawa (DD *
}

Tin (Sn) has a low melting temperature, i.e., $231.9^{\circ} \mathrm{C}$ for the bulk, and the capability to form compounds with many metals. The galvanic reaction between Sn nanoparticles (NPs) as the core and silver nitrate at room temperature under argon gas in an organic solvent without any reducing power, was employed for the first time to coat an $\mathrm{Ag}-\mathrm{Sn}$ intermetallic shell, i.e., $\mathrm{Ag}_{3} \mathrm{Sn}$ and/or $\mathrm{Ag}_{4} \mathrm{Sn}$, on $\mathrm{Sn} \mathrm{NPs}$. For spherical $\mathrm{Sn} \mathrm{NPs}$, the NPs retained a spherical shape after coating. Uniform and Janus structures consisting of a $\beta$-Sn core with $\mathrm{Ag}-\mathrm{Sn}$ shell were observed in the resulting NPs and their population related to the input molar ratios of the metal precursors. The observation of the intermetallic shell is general for both spherical and rod-shape Sn NPs. The formation of the intermetallic shell indicated that two reactions occurred sequentially, first reduction of $\mathrm{Ag}$ ions to $\mathrm{Ag}$ atoms by the $\mathrm{Sn}$ core, followed by interdiffusion of $\mathrm{Ag}$ and $\mathrm{Sn}$ to form the Ag-Sn intermetallic shell.

Received 22nd April 2019

Accepted 30th June 2019

DOI: $10.1039 / c 9 r a 02987 g$

rsc.li/rsc-advances

contrast, the reduction of Ag via galvanic reaction with Sn NPs

\section{Introduction}

Sn nanoparticles (NPs) have been used as phase change materials, ${ }^{1}$ for gas-sensing, ${ }^{2}$ conductive inks for printed electronics, ${ }^{3,4}$ lead-free solder in electronics and anode material in lithium and sodium-ion batteries. ${ }^{5-8}$ Similar to various alloy NPs, ${ }^{9-12}$ the catalytic properties, ${ }^{13-17}$ conductivity, ${ }^{18,19}$ and soldering properties ${ }^{20,21}$ can be further modified and improved by introducing $\mathrm{Ag}$ into the $\mathrm{Sn}$ NPs to form $\mathrm{Ag}$-Sn alloy NPs. ${ }^{13-16,18-21}$ The catalytic properties of Ag-Sn NPs were superior compared with that of Sn. ${ }^{13,15}$ In the work by Jo et al. ${ }^{19}$ highly conductive $\mathrm{Ag}-\mathrm{Sn}$ bimetallic NPs with various compositions (e.g., 80Ag20Sn, 60Ag40Sn, 40Ag60Sn and 20Ag80Sn) were synthesized using the polyol method. The synthesized NPs had low sheet resistance which could be applied in printed electronics. ${ }^{19}$ Jiang and coworkers have observed that the Ag-Sn alloy NPs had lower melting temperatures with decreasing particle size. ${ }^{20,21}$ The low melting point NPs were suitable as solders in lead-free interconnects. ${ }^{20,21}$

$\mathrm{Ag}-\mathrm{Sn}$ intermetallic alloy NPs have been synthesized via direct co-reduction of $\mathrm{Ag}$ and $\mathrm{Sn}$ at elevated temperature. ${ }^{19} \mathrm{In}$

Division of Materials Science and Engineering, Faculty of Engineering, Hokkaido University, Kita 13 Nishi 8, Kita-ku, Sapporo, 060-8628, Japan. E-mail: tetsu@eng. hokudai.ac.jp

$\uparrow$ Electronic supplementary information (ESI) available: Preparation of spherical Sn NPs and Sn nanorods as core; EDX mapping of Sn-Ag NPs synthesized at high temperature; calculated lattice parameter of $\mathrm{Sn} / \mathrm{Ag}-\mathrm{Sn}$ NPs for different $\mathrm{Sn}: \mathrm{Ag}$ ratios; STEM-HAADF, elemental mapping images, elemental composition, line profile of spherical Sn/Ag-Sn NPs; XRD patterns, SAED pattern, TEM image, and size distribution of $\mathrm{Sn}$ and $\mathrm{Sn} / \mathrm{Ag}$-Sn nanorods; EDX spectrum and d-spacing calculated from HR-TEM images of $\mathrm{Sn} / \mathrm{Ag}-\mathrm{Sn}$ nanorods. See DOI: 10.1039/c9ra02987g and formation of $\mathrm{Ag}-\mathrm{Sn}$ intermetallic NPs have been observed at $90{ }^{\circ} \mathrm{C}$ in oleylamine and $45{ }^{\circ} \mathrm{C}$ in hexadecylamine via in situ $\mathrm{X}$ ray diffraction during the galvanic exchange reaction and elemental mapping of the product. ${ }^{22}$ The results show the growth of $\mathrm{Ag}-\mathrm{Sn}$ part and a higher atomic concentration of $\mathrm{Ag}$ compared to $\mathrm{Sn}$ in the NPs after the exchange reaction, revealing the transformation of $\mathrm{Sn}$ to $\mathrm{Ag}-\mathrm{Sn}$ intermetallic compounds ( $\varepsilon-\mathrm{Ag}_{3} \mathrm{Sn}$ or/and $\left.\zeta-\mathrm{Ag}_{4} \mathrm{Sn}\right){ }^{22}$ The formation of $\mathrm{Ag}-\mathrm{Sn}$ intermetallic compound can also occur at room temperature when depositing $100 \mathrm{~nm}$-thick Sn on $50 \mathrm{~nm}$-thick $\mathrm{Ag}$ film via a vacuum evaporation method. ${ }^{23,24}$ However, to-date, a selective coating of Ag-Sn intermetallic compounds on Sn NPs at room temperature has not been reported. The coating of Sn with less active metals at high temperature is challenging as it results in a structure consisting of the less active metal as the core and Sn, which is more active as the shell. We have observed that high temperature coating of Sn NPs with Ag resulted in normal core/ shell structure with intermetallic Ag-Sn as the core, similar results with Kreigner et al.'s study, ${ }^{22}$ and $\mathrm{Sn}$ as the shell (Fig. S1†).

Thus, in the present study, $\beta$-Sn NPs were coated with Ag-Sn intermetallic compounds via a galvanic reaction of Sn NPs and Ag cations at room temperature. The resulting structure is a reverse core/shell, where $\mathrm{Sn}$ is the core and $\mathrm{Ag}-\mathrm{Sn}$ is the shell. The surface coating of Sn NPs was carried out in tert-butyl alcohol (TBA), which does not have any reducing power. With TBA, the reduction of Ag cations by Sn NPs was solely performed via the galvanic reaction due to the difference in potential between Sn and Ag. Since no additional reducing agent was used to reduce $\mathrm{Ag}^{+}$ions, the absence of $\mathrm{Ag}$ NPs as a byproduct 
after synthesis was expected. Room-temperature reactions and diffusion are beneficial for obtaining the reverse core/shell structure. The produced NPs were studied in detail to understand the reaction between $\mathrm{Ag}^{+}$ions and Sn NPs at room temperature.

\section{Experimental}

\subsection{Chemicals for spherical Sn NPs and Sn/Ag-Sn NPs}

Oleylamine (Kanto), tin(II) chloride anhydrous (Junsei), tin(II) acetate (Wako), lithium bis(trimethylsilyl)amide (Sigma Aldrich), diisobutylaluminium hydride (DIBAH) in $1.0 \mathrm{M}$ toluene (Kanto), poly(vinylpyrrolidone) (PVP) K-90 with MW 630000 (TCI), sodium borohydride (Wako), tert-butyl alcohol (TBA, Wako), silver nitrate (Junsei), and 1-propanol (Junsei) were used as received.

\subsection{Synthesis of Sn NPs as the core}

Spherical Sn NPs as the core were synthesized based on the modified method of Kravchyk et al. ${ }^{5}$ Sn nanorods (NRs) were also synthesized as the cores by using our previously reported method. ${ }^{25}$ Details of the synthesis procedures are given in the ESI.†

\subsection{Preparation of $\mathrm{Sn} / \mathrm{Ag}-\mathrm{Sn} \mathrm{NPs}$}

First Sn NPs of $0.25 \mathrm{mmol} \mathrm{Sn}$ atoms were dispersed in $20 \mathrm{~cm}^{3}$ TBA and sonicated for $10 \mathrm{~min}$ to form a dispersion of Sn NPs (0.0125 M Sn atoms). At the same time, a $0.0050 \mathrm{M}$ silver nitrate stock solution was prepared in a vial by adding $8.5 \mathrm{mg}$ silver nitrate to $10 \mathrm{~cm}^{3}$ TBA. The sonicated Sn NP dispersion was then purged under argon gas for $15 \mathrm{~min}$, followed by injection of 1 $\mathrm{cm}^{3}$ silver nitrate stock solution. The solution was stirred at $500 \mathrm{rpm}$ and reacted for $15 \mathrm{~min}$ at room temperature, i.e. $26^{\circ} \mathrm{C}$. The solution was then centrifuged using 1-propanol at $8000 \mathrm{rpm}$ for $10 \mathrm{~min}$. This purification step was repeated twice, and the purified Sn/Ag-Sn NPs were dispersed in 1-propanol for further characterization. Coatings of Sn NPs using $1 \mathrm{~cm}^{3}$ of $0.0125 \mathrm{M}$ and $0.0230 \mathrm{M}$ silver nitrate stock solutions were also performed as summarized in Table 1.

For the purpose of coating Sn NRs, $0.385 \mathrm{mmol} \mathrm{Sn}$ was dispersed in $77 \mathrm{~cm}^{3}$ TBA and then sonicated for $5 \mathrm{~min}$ to form a dispersion of Sn NRs with $\mathrm{Sn}$ atomic concentration of $0.0050 \mathrm{M} \mathrm{Sn}$. At the same time, $0.0892 \mathrm{M}$ silver nitrate stock solution was prepared in a vial by adding $0.3788 \mathrm{~g}$ silver nitrate into $25 \mathrm{~cm}^{3}$ of TBA. The sonicated Sn dispersion was purged under argon gas for $15 \mathrm{~min}$ while stirring at $800 \mathrm{rpm} .5 \mathrm{~cm}^{3}$ silver nitrate stock solution was then injected into the solution and left for $3 \mathrm{~h}$ at room temperature to allow the reaction to proceed. After reaction, the solution was centrifuged using 1propanol at $15000 \mathrm{rpm}$ for $30 \mathrm{~min}$. This purification step was repeated three times, and the product was dispersed in 1propanol for further characterization.

\subsection{Characterization}

The crystalline and phase structures of the NPs were characterized using X-ray diffraction (XRD, Rigaku Miniflex II X-ray diffractometer, $\mathrm{Cu} K \alpha$ radiation, $\lambda=1.5418 \AA$, scanning speed of $2^{\circ} \mathrm{min}^{-1}$ ). XRD samples were prepared by dropping $\sim 50$ $\mathrm{mm}^{3}$ dispersion of NPs onto the XRD sample plate. The morphologies and selected area electron diffraction (SAED) of the NPs were examined by a transmission electron microscopy (TEM, JEOL JEM-2000FX, 200 kV). High-resolution (HR) TEM and HAADF images were acquired using scanning transmission electron microscopies (STEM, FEI Titan Cube, $300 \mathrm{kV}$ and ARM200F, $200 \mathrm{kV}$ ). The TEM sample was prepared by releasing a drop of NPs dispersion onto a collodion-coated copper TEM grid. TEM/STEM-energy dispersive X-ray spectroscopy (EDX) was used to analyse the composition and elemental distribution of the NPs. The average size of NPs was estimated from 150 NPs in an arbitrarily chosen area of enlarged TEM images.

\section{Results and discussion}

\subsection{Crystal structure and morphology of Sn/Ag-Sn NPs}

Fig. 1 shows the XRD data for the as-synthesized $\beta$-Sn NPs and $\mathrm{Sn} / \mathrm{Ag}-\mathrm{Sn}$ NPs using various molar ratios of Sn and Ag. The synthesized Sn NPs had peaks in $2 \theta$ equal to $30.645^{\circ}, 32.019^{\circ}$, $43.872^{\circ}, 44.903^{\circ}, 55.332^{\circ}, 62.540^{\circ}, 63.785^{\circ}$, and $64.578^{\circ}$; all peaks can be indexed to the peaks of $\beta$-Sn. For $\mathrm{Sn} / \mathrm{Ag}-\mathrm{Sn}$ NPs, three additional small peaks were observed in the area marked with the rectangular box. The peaks at $2 \theta$ equal to $34.657^{\circ}$, $37.603^{\circ}$, and $39.589^{\circ}$ correspond to peaks of the $\mathrm{Ag}_{3} \mathrm{Sn}$ intermetallic compound. However, these three peaks may be also indexed to peaks of the $\mathrm{Ag}_{4} \mathrm{Sn}$ intermetallic compound. $\mathrm{Ag}_{4} \mathrm{Sn}$ intermetallic compound has peaks in $2 \theta$ equal to $34.911^{\circ}$, $37.588^{\circ}$, and $39.801^{\circ}$, which resemble those of $\mathrm{Ag}_{3} \mathrm{Sn}$. No metallic Ag peak was observed. The XRD pattern of the coated NPs confirmed the presence of the Ag-Sn intermetallic compound $\left(\mathrm{Ag}_{3} \mathrm{Sn}\right.$ and/or $\left.\mathrm{Ag}_{4} \mathrm{Sn}\right)$ in the NPs. When a higher ratio of the input $\mathrm{Ag}$ cations was used, more intense XRD peaks of the intermetallic compounds were observed. However, the peaks of Sn were more significant than those of the intermetallic compounds, suggesting that the Sn/Ag-Sn NPs were

Table 1 Concentration and amount of Sn and Ag used in coating experiments

\begin{tabular}{|c|c|c|c|c|}
\hline \multicolumn{2}{|c|}{ Sn NPs dispersion } & \multicolumn{2}{|c|}{$\mathrm{AgNO}_{3}$ solution } & \multirow[t]{2}{*}{ Mole ratio of $\mathrm{Sn}: \mathrm{Ag}^{+}$} \\
\hline Sn at. concentration (M) & Sn at. amount (mmol) & Concentration (M) & Amount (mmol) & \\
\hline 0.0125 & 0.250 & 0.0050 & 0.0050 & $1: 0.020$ \\
\hline 0.0125 & 0.250 & 0.0125 & 0.0125 & $1: 0.050$ \\
\hline \multirow[t]{2}{*}{0.0125} & 0.250 & 0.0230 & 0.0230 & $1: 0.092$ \\
\hline & sion & $\mathrm{AgN}$ & & \\
\hline 0.0050 & 0.385 & 0.0892 & 0.4460 & $1: 1.158$ \\
\hline
\end{tabular}




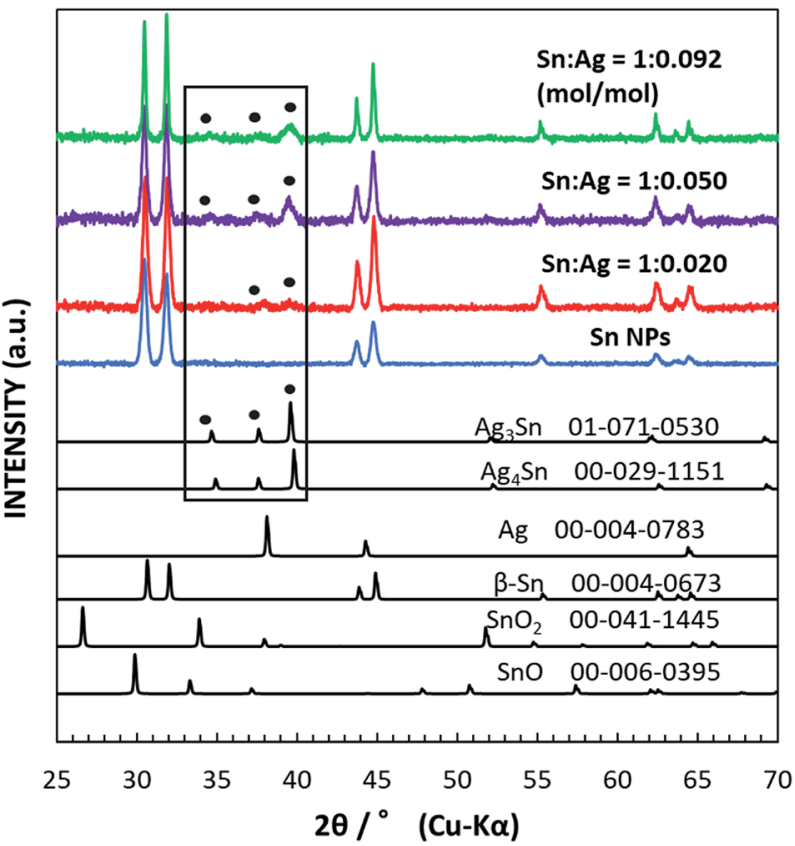

Fig. 1 XRD patterns of the as-synthesized Sn NPs (blue curve) and Sn/ $\mathrm{Ag}-\mathrm{Sn}$ NPs with various input molar ratios of $\mathrm{Sn}$ and $\mathrm{Ag}$, i.e., $\mathrm{Sn}: \mathrm{Ag}=$ $1: 0.020$ (red curve), $1: 0.050$ (violet curve), and $1: 0.092(\mathrm{~mol} / \mathrm{mol}$ ) (green curve). Reference patterns of $\beta$-Sn (JCPDS no. 04-0673), SnO (JCPDS no. 06-0395), $\mathrm{SnO}_{2}$ (tetragonal, JCPDS no. 41-1445), Ag (JCPDS no. 004-0783), $\mathrm{Ag}_{3} \mathrm{Sn}$ (JCPDS no. 071-0530), and $\mathrm{Ag}_{4} \mathrm{Sn}$ (JCPDS no. 029-1151) are shown in black. The black box is for visual guidance to the peaks in the samples which were assigned as intermetallic compounds labelled with filled circles.

mainly dominated by Sn with smaller amounts of Ag-Sn intermetallic compounds. It should be noted that the solvent has no reducing power to $\mathrm{Ag}$ cations. Thus, the existence of the intermetallic compounds suggests that the galvanic reaction occurred and $\mathrm{Ag}$ cations were reduced by Sn. The formation of the $\mathrm{Ag}$-Sn intermetallic compounds as observed at room temperature via the galvanic reaction of Sn NPs and Ag cations in an organic solvent is the key result. The use of $\mathrm{Ag}$ for coating Sn nanoparticles has always been reported at elevated temperature without any reducing agent or at room temperature in the presence of reducing agent or in solvents which possess reducing power, i.e., hexylamine, oleylamine and ethanol. ${ }^{19,21,26-29}$ The formation of the intermetallic compound between $\mathrm{Ag}$ and $\mathrm{Sn}$ has been achieved at room temperature without any reducing agent but it was carried out through vacuum evaporation of $\mathrm{Sn}$ on $\mathrm{Ag}$ thin film..$^{23,24}$ Our observation demonstrated that intermetallic compounds were formed in the organic solvent under the galvanic reduction of the Ag cation by $\mathrm{Sn}$ at room temperature. The formation and distribution of the intermetallic compounds on Sn NPs will be analysed and discussed more in depth in the following sections.

Fig. 2 shows the TEM images of the as-synthesized spherical Sn NPs (Fig. 2a) and the Sn/Ag-Sn NPs (Fig. 2c) with $\mathrm{Sn}: \mathrm{Ag}=$ $1: 0.020(\mathrm{~mol} / \mathrm{mol})$. The Sn NPs used for coating had an average size of $31.4 \pm 8.2 \mathrm{~nm}$ (Fig. 2e). The bright spots in the SAED pattern of Sn NPs (Fig. 2b) were indexed to planes of $\beta$-Sn,
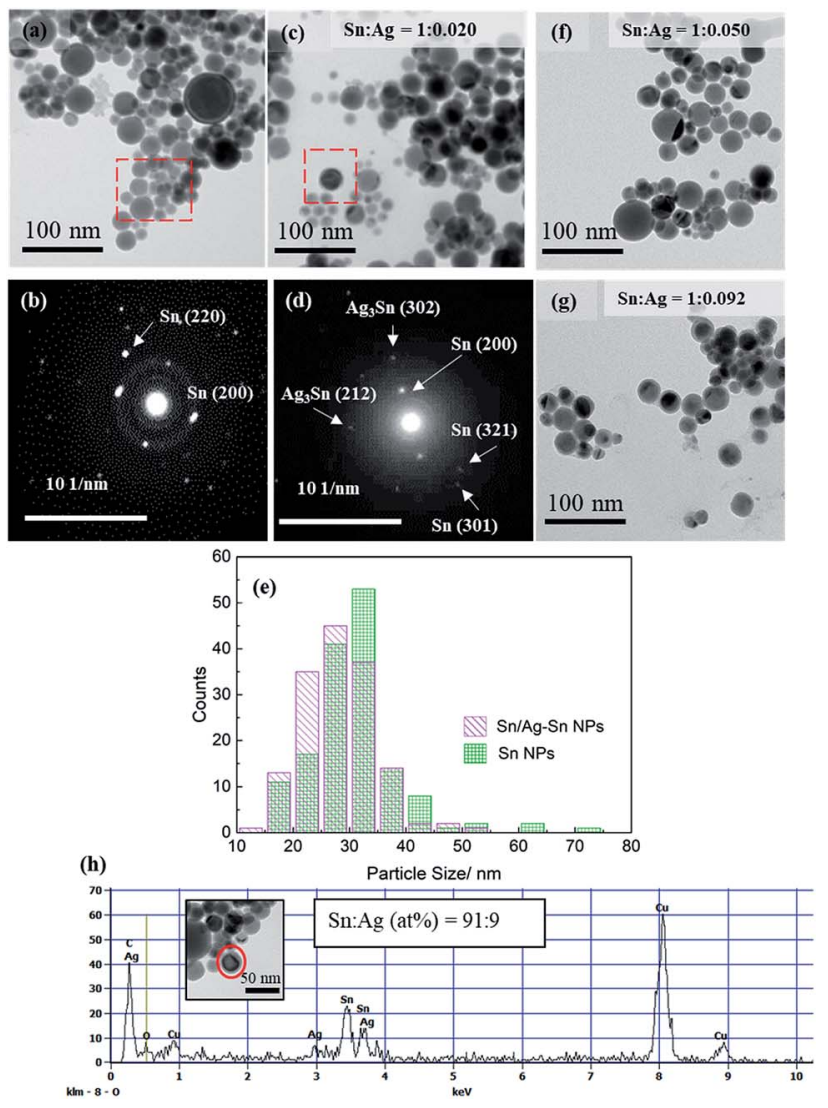

Fig. 2 (a) TEM image and (b) SAED of Sn NPs. (c) TEM image and (d) SAED pattern of $\mathrm{Sn} / \mathrm{Ag}-\mathrm{Sn}$ NPs $(\mathrm{Sn}: \mathrm{Ag}=1: 0.020(\mathrm{~mol} / \mathrm{mol}))$. (e) Size distributions of Sn NPs and Sn/Ag-Sn NPs shown in (a) and (c), respectively. (f) TEM image of $\mathrm{Sn} / \mathrm{Ag}-\mathrm{SnN} N \mathrm{~S}(\mathrm{Sn}: \mathrm{Ag}=1: 0.050(\mathrm{~mol} /$ $\mathrm{mol}))$, (g) TEM image of Sn/Ag-Sn NP (Sn: Ag = 1: $0.092(\mathrm{~mol} / \mathrm{mol}))$ and (h) EDX spectra of an Sn/Ag-Sn NP (Sn : Ag = 1 : $0.020(\mathrm{~mol} / \mathrm{mol})$ ). The $\mathrm{Cu}$ signals in EDX spectrum came from the collodion-coated $\mathrm{Cu}$ grid used for preparing the sample.

confirming that the Sn NPs were $\beta$-Sn. There was a thin layer around the NPs which could be amorphous tin oxides since no crystalline tin oxides were observed in either XRD or SAED patterns. The oxide layers might be formed during purification when the Sn NPs were exposed to air during solvent exchange, as reported for Sn NPs synthesized using the same method by Kravchyk and coworkers. ${ }^{5}$ The Sn/Ag-Sn NPs remained spherical after galvanic reaction for all the input molar ratios of $\mathrm{Sn}$ and $\mathrm{Ag}$ (Fig. 2c, f, and g). The average size of the NPs was $28.4 \pm$ $6.3 \mathrm{~nm}$ (Fig. 2e) for $\mathrm{Sn}: \mathrm{Ag}=1: 0.020(\mathrm{~mol} / \mathrm{mol})$, similar to $\mathrm{Sn}$ NPs which were used as the core. The bright spots in the SAED pattern of the NPs (Fig. 2d) could be indexed to planes of $\beta$-Sn and $\mathrm{Ag}$-Sn intermetallic compounds $\left(\mathrm{Ag}_{3} \mathrm{Sn}\right.$ and/or $\left.\mathrm{Ag}_{4} \mathrm{Sn}\right)$. EDX point analysis for a single Sn/Ag-Sn NP (Fig. $2 \mathrm{~h}$ ) further proved that elemental Ag was present in the coated Sn NP. There was no yolk-shell structure observed in TEM images suggesting that the galvanic reaction occurred with the inward diffusion of the $\mathrm{Ag}$ cation into the Sn core and outward diffusion of the Sn cation through the oxide shell at room temperature. Kriegner et al. have reported similar observations when the reaction was performed in oleylamine at a higher temperature. ${ }^{22}$ 


\subsection{HR-TEM, HAADF, and elemental mapping of Sn/Ag-Sn} NPs

To understand the fine structure of the Sn/Ag-Sn NPs, HR-TEM was used. Fig. 3 shows the HR-TEM images of Sn/Ag-Sn NPs with the input ratio of $\mathrm{Sn}: \mathrm{Ag}=1: 0.020,1: 0.050$, and $1: 0.092(\mathrm{~mol} / \mathrm{mol})$. Based on both TEM and HR-TEM images, the $\mathrm{Sn} / \mathrm{Ag}-\mathrm{Sn}$ NPs were categorized into either a uniform structure or a Janus structure. For uniform structures, most NPs showed lattice spacings, which were assigned to Ag-Sn (Fig. 3, Tables S1-S3†). The lattice of such NPs was indexed to the planes of $\mathrm{Ag}_{3} \mathrm{Sn}$ or $\mathrm{Ag}_{4} \mathrm{Sn}$. In this case, the $\mathrm{Ag}^{+}$ions, which were injected into the solution, reacted completely with the surface of Sn NPs to form the intermetallic compound. In contrast, there were some NPs exhibiting the uniform structure but their lattice spacings were indexed to the (200) and (220) planes of pure $\beta$-Sn (Fig. S2 $\dagger$ ). In this case, the Sn NPs did not react with $\mathrm{Ag}^{+}$ions to form the $\mathrm{Ag}-\mathrm{Sn}$ intermetallic compound. This might be due to insufficient $\mathrm{Ag}^{+}$in the reaction solution.

For Sn/Ag-Sn NPs exhibiting a Janus structure, the lattice of the NPs was indexed to (200) plane of $\beta$-Sn, (201) plane of $\mathrm{Ag}_{3} \mathrm{Sn}$ or (100) plane of $\mathrm{Ag}_{4} \mathrm{Sn}$. In Janus structures, a portion of the NPS was the Ag-Sn intermetallic compound, while the other portion was pure $\beta$-Sn. The existence of a Janus structure also suggests
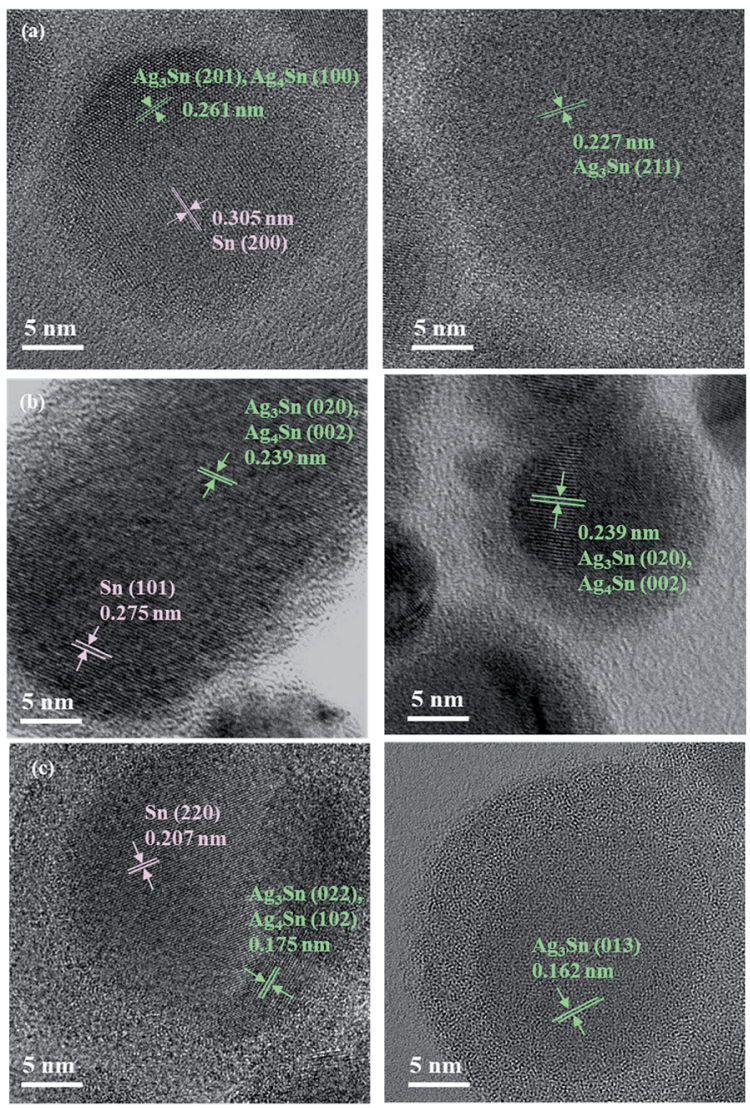

Fig. 3 HR-TEM images of Sn/Ag-Sn NPs with various input molar ratios of $\mathrm{Sn}$ and $\mathrm{Ag}$, (a) $\mathrm{Sn}: \mathrm{Ag}=1: 0.020$, (b) $1: 0.050$, and (c) 1: $0.092(\mathrm{~mol} / \mathrm{mol})$, showing both Janus and uniform structures. Green lines and arrows are for the Ag-Sn portion in the NPs while pink lines and arrows indicate the Sn portion. that its formation could be attributed to a deficiency of $\mathrm{Ag}^{+}$ions available to react with Sn NPs. Since the coated NPs might be full $\mathrm{Ag}$-Sn intermetallic compound NPs, HAADF and elemental mapping analysis were performed to understand the composition of Sn and $\mathrm{Ag}$ in the coated NPs. Fig. 4 shows the HAADF and corresponding elemental mapping of both uniform and Janus NPs which exhibited the intermetallic compound.

A NP will consist of 24-25 at\% (atomic percentages) Sn and $75-76$ at\% $\mathrm{Ag}$ if it is an $\varepsilon-\mathrm{Ag}_{3} \mathrm{Sn} \mathrm{NP}$; and 12-22 at\% Sn with 78-88 at\% $\mathrm{Ag}$ if it is a $\zeta-\mathrm{Ag}_{4} \mathrm{Sn}$ NP. Based on elemental mapping data of several uniform NPs (Fig. 4 and Fig. S3†), the atomic percentage of Sn was always higher than Ag, confirming that uniform NPs were dominated by the Sn element. This result suggested that the NPs had a Sn core with an Ag-Sn intermetallic compound shell instead of being fully $\mathrm{Ag}-\mathrm{Sn}$ intermetallic compounds. There were several uniform NPs (particle numbers 6, 13, and 14 in Fig. S3†) which had higher atomic percentage of $\mathrm{Ag}$ than that of Sn. However, this was less than the 75-76 at\% Ag of the Ag-Sn intermetallic compound. These types of NPs might have a smaller Sn core with a thick intermetallic shell. However, this type of NPs was less frequently observed in the overall sample of NPs. For Janus NPs, all the NPs (numbers 2, 4, 7, 8, and 12 in Fig. S3†) had a higher atomic percentage of Sn. There are two portions which were assigned to $\beta$-Sn and the Ag-Sn intermetallic compound, respectively, in a Janus structure NP. Elemental mapping analysis on the Ag-Sn portions of the Janus NPs (Fig. S4 $\dagger$ ) showed that they had higher atomic percentages of $\mathrm{Sn}$ than that of the $\mathrm{Ag}$, i.e., $\mathrm{Sn}: \mathrm{Ag}=68: 32$ for the Janus NP number 2 in Fig. 4. This result suggests that the Ag-Sn portion of the NPs consisted of a Sn core with an Ag-Sn shell. In short, Janus structure NPs could be depicted as Sn NPs partially coated with an Ag-Sn intermetallic shell.

\subsection{Effect of $\mathrm{Ag}^{+}$cations concentrations on the structure of Sn/Ag-Sn NPs}

The $\mathrm{Sn} / \mathrm{Ag}-\mathrm{Sn}$ NPs synthesized by using an input ratio of $\mathrm{Sn}: \mathrm{Ag}$ $=1: 0.020(\mathrm{~mol} / \mathrm{mol})$ were either pure $\beta$-Sn NPs, $\beta$-Sn NPs partially coated or fully coated with an $\mathrm{Ag}-\mathrm{Sn}$ shell. This result suggests that at such a low input ratio of $\mathrm{Ag}^{+}$cations compared with $\mathrm{Sn}$, the availability of $\mathrm{Ag}$ might be insufficient to allow all
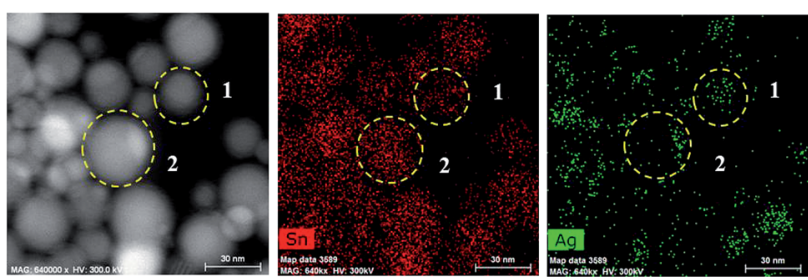

\begin{tabular}{|c|c|c|c|}
\hline \multirow{2}{*}{ NP No. } & \multicolumn{2}{|c|}{ Atomic \% } & \multirow{2}{*}{ Structure } \\
\hline & Sn & $\mathrm{Ag}$ & \\
\hline 1 & 75 & 25 & Uniform \\
\hline 2 & 91 & 9 & Janus \\
\hline
\end{tabular}

Fig. 4 HAADF, elemental mapping and table corresponding to the atomic percentages of $\mathrm{Sn}$ and $\mathrm{Ag}$ in $\mathrm{Sn} / \mathrm{Ag}-\mathrm{Sn}$ NPs number 1-2 (information on NPs number 3-15 is available in Fig. S3 in ESI†). 
Sn NPs to be fully coated with an Ag-Sn shell. The effect of $\mathrm{Ag}^{+}$ concentrations on the distribution of uniform and Janus structure NPs was studied using TEM images by identifying the NPs that had a clear Janus structure and the results are shown in Fig. 5. When higher concentration of $\mathrm{Ag}^{+}$was present in the solution, Janus structures still existed (Fig. $3 \mathrm{~b}$ and c), but the number of NPs with the Janus structure significantly decreased. When the input ratio of $\mathrm{Ag}$ was increased, i.e., $\mathrm{Sn}: \mathrm{Ag}$ varied from $1: 0.020(\mathrm{~mol} / \mathrm{mol})$ to $1: 0.092(\mathrm{~mol} / \mathrm{mol})$, the percentage of NPs with the Janus structure decreased from $37 \%$ to $20 \%$. This suggests that a higher $\mathrm{Ag}^{+}$concentration will produce more uniform structures and fewer Janus structure NPs after coating. Since the percentage of Janus NPs decreased and the relative intensity of XRD peaks of the intermetallic compound (Fig. 1) increased with increasing $\mathrm{Ag}^{+}$input ratios, we conclude that the Sn NPs were coated with an Ag-Sn shell and more uniform coating were achieved with a higher input ratio of $\mathrm{Ag}^{+}$.

Based on the elemental mappings of NPs (Fig. 4, S3 and S5 $\dagger$ ), the average atomic percentage of $\mathrm{Ag}$ in uniform NPs increased from $28 \%$ to $45 \%$ when $\mathrm{Sn}: \mathrm{Ag}$ varied from $1: 0.020(\mathrm{~mol} / \mathrm{mol})$ to $1: 0.092(\mathrm{~mol} / \mathrm{mol})$. With a higher concentration of $\mathrm{Ag}^{+}$ present in the solution, more $\mathrm{Ag}^{+}$can be reduced to $\mathrm{Ag}$ atoms. More Ag atoms were then available for interdiffusion between $\mathrm{Sn}$ and $\mathrm{Ag}$ to form the $\mathrm{Ag}-\mathrm{Sn}$ intermetallic shell on $\beta$-Sn cores. When the concentration of $\mathrm{Ag}^{+}$increased, some NPs were transformed to full Ag-Sn NPs, although most of the NPs still possessed a Sn core with an Ag-Sn shell structure. Since the amount of Ag was still deficient to fully cover the surfaces of all NPs, some NPs remained partially coated with the Ag-Sn shell (Janus structure) while some were pure Sn NPs.

\subsection{Formation of Ag-Sn intermetallic shell on Sn NPs}

From all the syntheses, it was evident that the $\mathrm{Ag}-\mathrm{Sn}$ intermetallic compound formed on Sn NPs regardless of the concentration of $\mathrm{Ag}^{+}$. The formation of the $\mathrm{Ag}-\mathrm{Sn}$ intermetallic compound can be explained by the operation of two sequential processes (Fig. 6).

First, $\mathrm{Ag}^{+}$ions that penetrated through the surface tin oxide were reduced to $\mathrm{Ag}$ atoms by the $\mathrm{Sn}$ atoms on the surface of $\mathrm{Sn}$

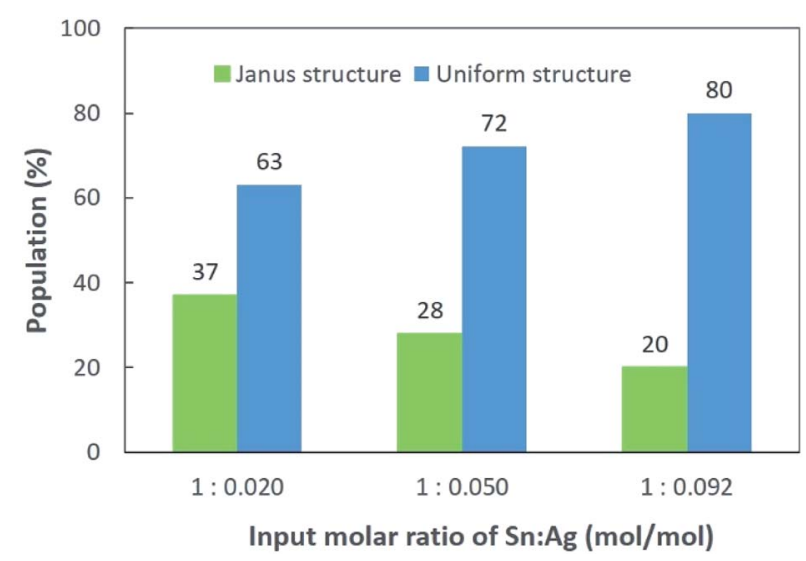

Fig. 5 Distribution of Janus and uniform structures of Sn/Ag-Sn NPs with various input molar ratios of $\mathrm{Sn}$ and $\mathrm{Ag}$, i.e., $\mathrm{Sn}: \mathrm{Ag}=1: 0.020$, $1: 0.050$, and $1: 0.092(\mathrm{~mol} / \mathrm{mol})$.
NPs via galvanic reaction. $\mathrm{Sn}^{2+}$ ions were released during this reaction through the tin oxide shell. Once Ag atoms formed, the $\mathrm{Sn}$ atoms on the surface of NPs then diffused into $\mathrm{Ag}$ to form the $\mathrm{Ag}-\mathrm{Sn}$ intermetallic compound. This is because the diffusion rate of low-melting point metals such as Sn into $\mathrm{Ag}$ is high; the interdiffusion coefficient is approximately $3.4 \times 10^{-16} \mathrm{~cm}^{2}$ $\mathrm{s}^{-1} \cdot{ }^{23,24}$ The large difference in surface energy of $\operatorname{Sn}\left(0.675 \mathrm{~J} \mathrm{~m}^{-2}\right)$ and $\mathrm{Ag}\left(1.250 \mathrm{~J} \mathrm{~m}^{-2}\right)$ is the reason for the upward diffusion of $\mathrm{Sn}$ into the growing $\mathrm{Ag}$ layer. ${ }^{\mathbf{3 0 - 3 2}}$ The formation of the intermetallic compound will be completed faster with the presence of higher concentrations of $\mathrm{Sn}$, which was the typical condition of our experiments wherein the maximum molar input of $\mathrm{Ag}$ was less than $1 \%$ of Sn. Clearly, Ag-Sn intermetallic compounds were easily formed, even at room temperature.

Similar observations were obtained when using Sn NRs as the Sn core for coating (Fig. S6-S8†). The Sn NRs before coating (Fig. S7†) had a tin oxide layer on the surface and some small spherical Sn NPs existed along with NRs in the sample. Fig. 7 shows the HR-TEM images of $\mathrm{Sn} / \mathrm{Ag}-\mathrm{Sn}$ NRs. Based on these images, the lattices of coated NRs were indexed to (200) of $\beta$-Sn, (022) of $\mathrm{Ag}_{3} \mathrm{Sn}$ and (311) of $\mathrm{Ag}$ (Table $\mathrm{S} 4 \dagger$ ). The inner part of the NRs was made up of Sn. There was a thin layer of intermetallic compound on the Sn core. On the surface of the intermetallic compound layer, Ag islands were observed. Elemental mapping and line scan on the coated NRs (Fig. 7) revealed that elemental $\mathrm{Ag}$ was present on all the surface area of NRs. Since Ag had the same location as the $\mathrm{Sn}$, it was reasonable to propose that the NRs were covered by Ag-Sn intermetallic compound.

The results observed in Sn/Ag-Sn NRs also suggested that the $\mathrm{Ag}^{+}$ions, which were injected into the solution, reacted completely with $\mathrm{Sn}$ on the surface of NRs to form an intermetallic compound layer. As observed in the coating using spherical Sn NPs as the core, some NRs were not coated. The important finding here is that even at room temperature, intermetallic compounds were formed on Sn NRs, below an amorphous layer, which may have been composed of tin oxides. The presence of Ag NPs was observed on the uppermost surface of $\mathrm{Sn}$ coated with $\mathrm{Ag}-\mathrm{Sn}$ and an amorphous layer. This $\mathrm{Ag}$ is thought to be the product of the complete reduction of small spherical Sn NPs and $\mathrm{Ag}^{+}$in the reaction solution due to the

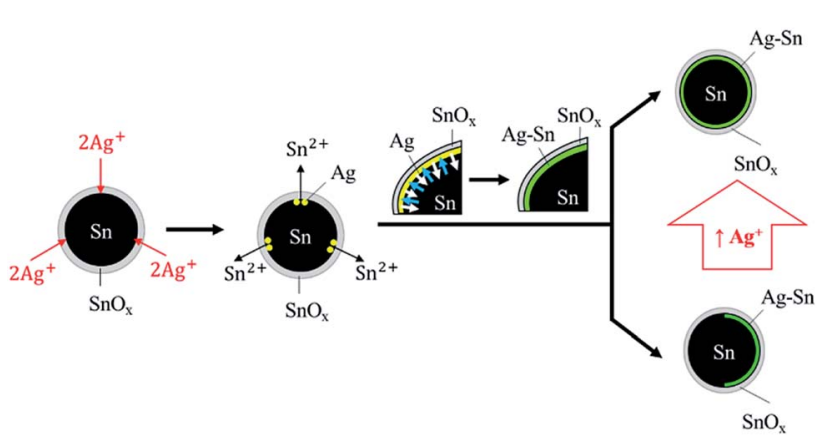

Fig. 6 Coating of $\mathrm{Ag}-\mathrm{Sn}$ intermetallic compound on Sn NPs via sequential steps: reduction of $\mathrm{Ag}^{+}$by $\mathrm{Sn}$ and interdiffusion of $\mathrm{Sn}$ and $\mathrm{Ag}$ ( $\mathrm{Sn}$ into $\mathrm{Ag}$ as shown by blue arrows; $\mathrm{Ag}$ into $\mathrm{Sn}$ as shown by white arrows). More uniform Sn/Ag-Sn NPs can be obtained with higher concentration of $\mathrm{Ag}^{+}$. 

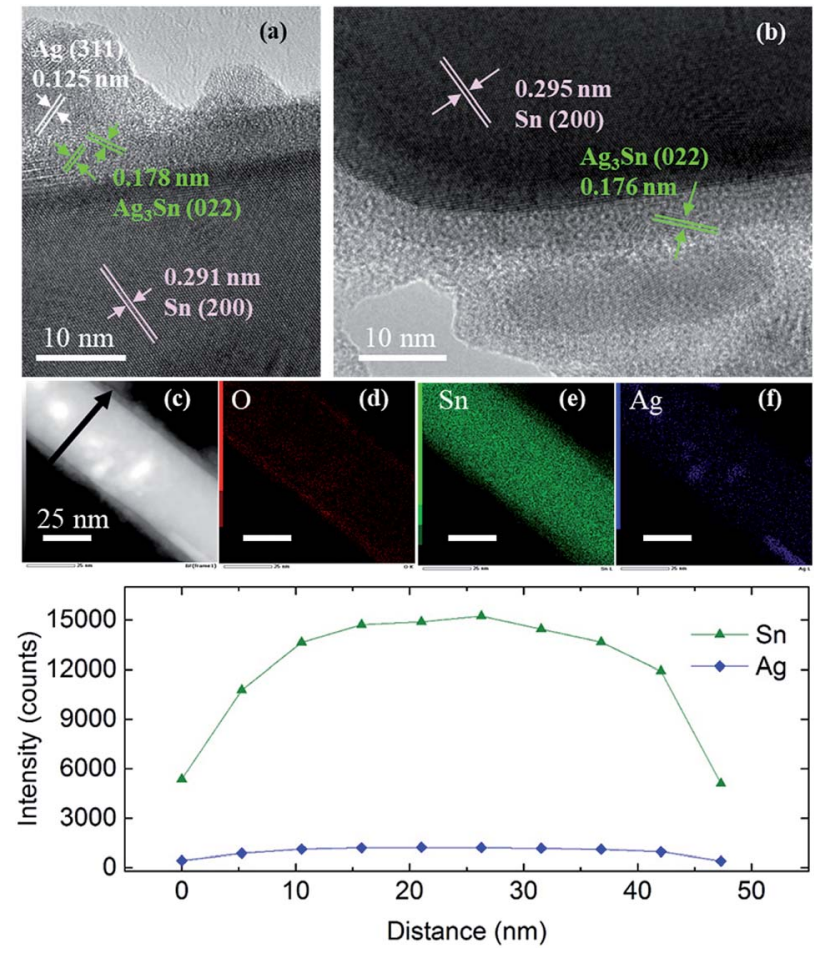

Fig. 7 (a and b) HR-TEM images of $\mathrm{Sn} / \mathrm{Ag}-\mathrm{Sn} \mathrm{NRs}$, (c) HAADF, (d-f) elemental mappings of the NR shown in (c), and ( $\mathrm{g}$ ) line profiles along the arrow in (c)

higher surface area of small spherical Sn NPs and the higher amount of $\mathrm{Ag}^{+}$used, along with a long reaction time. In addition, the binding energy of $\mathrm{Ag}-\mathrm{Ag}$ is around $163 \mathrm{~kJ} \mathrm{~mol}^{-1}$, which is higher than that of the Ag-Sn bond, which is approximately $136 \mathrm{~kJ} \mathrm{~mol}^{-1} \cdot{ }^{33}$ This is possibly the reason for $\mathrm{Ag}$ atoms to bond with each other to form Ag NPs. In a recent study of coating Ag onto Sn NRs, the as-synthesized Sn/Ag NRs consisted of only Sn NRs with Ag NPs dispersed on the surface of NRs and no intermetallic compound existed. ${ }^{34}$ These observations are similar with our current study, however, the presence of a very thin layer of intermetallic compound between Sn NRs and Ag NPs was likely to have been overlooked in their study.

\section{Conclusions}

Coating of a layer of $\mathrm{Ag}-\mathrm{Sn}$ intermetallic compounds on Sn NPs was achieved at room temperature via galvanic reaction. The $\mathrm{Sn} /$ $\mathrm{Ag}-\mathrm{Sn}$ NPs retained the original shape of $\mathrm{Sn}$ and had a similar particle size after coating. The coated spherical Sn NPs were either uniform structure NPs or Janus structure NPs, wherein the uniform structure was comprised mainly of $\mathrm{Sn} / \mathrm{Ag}-\mathrm{Sn}$ core/ shell NPs with some pure Sn NPs and the Janus structure composed of a $\mathrm{Sn}$ core with a partially coated $\mathrm{Ag}-\mathrm{Sn}$ intermetallic shell. The Ag-Sn intermetallic shell was formed via two sequential steps. First, $\mathrm{Ag}^{+}$ions penetrated through the surface oxide layer of Sn NPs and were reduced to Ag by Sn via galvanic reaction. Then, interdiffusion between $\mathrm{Sn}$ and $\mathrm{Ag}$ occurred to form an $\mathrm{Ag}-\mathrm{Sn}$ intermetallic shell. Due to the presence of insufficient $\mathrm{Ag}^{+}$ions in the solution, some Sn NPs were partially coated while some were not coated. By increasing the concentration of $\mathrm{Ag}^{+}$in the solution, more uniform $\mathrm{Sn} / \mathrm{Ag}-\mathrm{Sn}$ NPs could be obtained.

\section{Conflicts of interest}

There are no conflicts to declare.

\section{Acknowledgements}

The authors thank Dr Y. Ishida, Mr H. Tsukamoto, Dr L. M. Z. De Juan-Corpuz (Hokkaido University) for fruitful discussions. We acknowledge Mr T. Tanioka and Mr R. Oota (Hokkaido University) for their support in TEM and STEM. MJS thanks MEXT Scholarship for financial support during her stay in Sapporo. The research was partially supported by Grant-in-Aid for Scientific Research (B) (to TY, 18H01820) and that of Young Researcher B (to MTN, 17K14072). This work was partially performed under the Cooperative Research Program of "Network Joint Research Center for Materials and Devices" (20191253) and the JSPS A3 Foresight Program "Organic/ Inorganic Nanohybrid Platforms for Precision Tumor Imaging and Therapy".

\section{References}

1 S. Cingarapu, D. Singh, E. V. Timofeeva and M. R. Moravek, Int. J. Energy Res., 2014, 38, 51.

2 C. Nayral, E. Viala, P. Pau, F. Senocq, J.-C. Jumas, A. Maisonnat and B. Chaudret, Chem. -Eur. J., 2010, 6, 4082.

3 Y. H. Jo, I. Jung, C. S. Choi, I. Kim and H. M. Lee, Nanotechnology, 2011, 22, 225701.

4 H. Shirai, M. T. Nguyen, Y. Ishida and T. Yonezawa, J. Mater. Chem. C, 2016, 4, 2228.

5 K. Kravchyk, L. Protesescu, M. I. Bodnarchuk, F. Krumeich, M. Yarema, M. Walter, C. Guntlin and M. V. Kovalenko, J. Am. Chem. Soc., 2013, 135, 4199.

6 D. M. Seo, C. C. Nguyen, B. T. Young, D. R. Heskett, J. C. Woicik and B. L. Lucht, J. Electrochem. Soc., 2015, 162, A7091.

7 L. M. Z. De Juan, I. V. B. Maggay, M. T. Nguyen, W.-R. Liu and T. Yonezawa, ACS Appl. Nano Mater., 2018, 1, 3509.

8 C. Kim, K.-Y. Lee, Y. Kim, J. Park, G. Cho, K.-W. Kim, J.-H. Ahn and H.-J. Ahn, J. Power Sources, 2016, 317, 153.

9 T. Asset, R. Chattot, M. Fontana, B. Mercier-Guyon, N. Job, L. Dubau and F. Maillard, ChemPhysChem, 2018, 19, 1552.

10 M. T. Nguyen and T. Yonezawa, Sci. Technol. Adv. Mater., 2018, 19, 883.

11 T. Yonezawa, D. Čempel and M. T. Nguyen, Bull. Chem. Soc. Jpn., 2018, 91, 1781.

12 N. Toshima and T. Yonezawa, New J. Chem., 1998, 22, 1179.

13 Q. Wang, F. Chen, Y. Liu, T. T. Gebremariam, J. Wang, L. An and R. L. Johnson, J. Power Sources, 2018, 404, 106.

14 X. Zhang, F. Li, Y. Zhang, A. M. Bond and J. Zhang, J. Mater. Chem. A, 2018, 6, 7851.

15 W. Luc, C. Collins, S. Wang, H. Xin, K. He, Y. Kang and F. Jiao, J. Am. Chem. Soc., 2017, 139, 1885. 
16 C.-R. Liu, L.-S. Pan, C.-H. Li, H.-R. Chen and C.-L. Lee, J. Electrochem. Soc., 2015, 162, D283.

17 W. Kim, S. Lee and Y. Sohn, Sci. Rep., 2015, 5, 13448, DOI: 10.1038/srep13448.

18 S. S. Chee and J.-H. Lee, Thin Solid Films, 2014, 562, 211.

19 Y. H. Jo, I. Jung, N. R. Kim and H. M. Lee, J. Nanopart. Res., 2012, 14, 782.

20 H. Jiang, K.-S. Moon, F. Hua and C. P. Wong, Chem. Mater., 2007, 19, 4482 .

21 H. Jiang, K. Moon, F. Hua and C. P. Wong, Electronic Comp. Technol. Conf., 2007, vol. 54.

22 D. Kriegner, M. Sytnyk, H. Groiss, M. Yarema, W. Grafeneder, P. Walter, A. Dippel, M. Meffert, D. Gerthsen, J. Stangl and W. Heiss, J. Phys. Chem. C, 2016, 120, 19848.

23 Ž. Marinković and V. Simić, Thin Solid Films, 1991, 195, 127. 24 Ž. Marinković and V. Simić, Thin Solid Films, 1992, 217, 26. 25 L. M. Juan, M. T. Nguyen, T. Yonezawa, T. Tokunaga, H. Tsukamoto and Y. Ishida, Cryst. Growth Des., 2017, 17, 4554.

26 C. Zou, Y. Gao, B. Yang and Q. Zhai, J. Mater. Sci.: Mater. Electron., 2010, 21, 868.
27 H. J. Pan, C. Y. Lin, U. S. Mohanty and J. H. Chou, Mater. Sci. Appl., 2011, 2, 1480.

28 W. Zhang, B. Zhao, C. Zou, Q. Zhai, Y. Gao and S. F. A. Acquah, J. Nanomater., 2013, 193725.

29 Z. Jiang, S. Ding, Y. Tian and C. Wang, 15th Int. Confer. Electron. Packaging Technol., 2014, p. 1499, DOI: 10.1109/ ICEPT.2014.6922938.

30 P. Rossi, N. Zotov and E. J. Mittermeijer, Surf. Coat. Technol., 2016, 295, 88.

31 L. Vitos, A. V. Ruban, H. L. Skriver and J. Kollár, Surf. Sci., 1998, 411, 186.

32 N. Samy, S. S. Shenouda, M. Fadel, H. Talaat, G. L. Katona, G. A. Langer, A. Csik and D. L. Beke, Philos. Mag., 2015, 95, 2990.

33 Y.-R. Luo, Chapter 9 BDEs of $\mathrm{Si}^{-}, \mathrm{Ge}-, \mathrm{Sn}-$, and $\mathrm{Pb}-\mathrm{X}$ bonds. Chapter 21 BDEs of $\mathrm{Cu}\left(\mathrm{Cu}^{ \pm}\right)-, \mathrm{Ag}\left(\mathrm{Ag}^{ \pm}\right)-$, and $\mathrm{Au}(\mathrm{Au} \pm)-\mathrm{X}$ bonds, in Comprehensive Handbook of Chemical Bond Energies, CRC Press, Boca Raton, FL, 2007.

34 J. Xie, Y. Ji, D. Mao, F. Zhang, X. Fu, R. Sun and C. Wong, ACS Appl. Nano Mater., 2018, 1, 1531. 